J. Dairy Sci. 92:837-846

doi:10.3168/jds.2008-1125

(c) American Dairy Science Association, 2009.

\title{
Evaluation of the allergenicity of goat milk, cow milk, and their lactosera in a guinea pig model
}

\author{
L. Sanz Ceballos, M. R. Sanz Sampelayo, ${ }^{1}$ F. Gil Extremera, and M. Rodríguez Osorio \\ Consejo Superior de Investigaciones Científicas, Estación Experimental del Zaidín, Unidad de Nutrición Animal, \\ Profesor Albareda, 1, 18008 Granada, Spain
}

\begin{abstract}
The object of this study was to determine the allergenicity of goat milk (GM) and cow milk (CM) and that of their respective lactosera (GML and CML), by in vivo and in vitro assays. Two systemic tests for anaphylaxis were carried out in guinea pigs, the animals being sensitized orally with the 2 types of milk and lactosera. Sera were taken from the orbital sinus of the experimental animals at 0 and $22 \mathrm{~d}$ of the experiment to perform the serological study and the passive cutaneous anaphylaxis test. For the latter, the guinea pigs were sensitized passively with antibodies against the 4 antigen solutions. Enzyme-linked immunosorbent assay and Western blot were used to determine the specific antibodies of the isotypes immunoglobulin G1 and immunoglobulin $\mathrm{G}(\mathrm{Fc})$ developed against the same 4 antigen solutions. From these anaphylaxis and antibody-production tests, it was concluded that GM is hypoallergenic when compared with CM. The lactosera produced more closely grouped results, with values always below those of the corresponding milk. None of the proteins in the 4 immunizing solutions were identified as being their main allergen. These results show the hypoallergenicity of GM versus CM, and also that both casein and lactoserum proteins may be responsible for allergy in each case. To analyze the possibility of producing an innocuous food for those allergic to milk proteins, it would be of interest to identify the epitope(s) responsible for such allergenicity.
\end{abstract}

Key words: allergenicity, serology, goat and cow milk, goat and cow milk lactosera

\section{INTRODUCTION}

Cow milk protein allergy (CMPA) is a common disorder in childhood. As observed by Park (1994), most children under $3 \mathrm{yr}$ of age have circulating antibodies against milk protein, and in Western countries, up to

Received February 26, 2008.

Accepted November 6, 2008.

${ }^{1}$ Corresponding author: rsanz@eez.csic.es
$7 \%$ of these children produce an allergenic symptom against milk protein.

The first description of a milk allergy was made by F. Hamburger (1901; Wien. Klin. Wochenschr. 49:1202), as cited in Saperstein (1974), who detected a severe reaction in a boy given cow milk (CM). Today, it is well known that the proteins in CM, in certain circumstances, are responsible for hypersensitivity reactions, not only in infants, but also among children and adults. The most common alternatives to CM are soy milk and hydrolyzed formula. However, there is evidence that 10 to $40 \%$ of children with CMPA cannot tolerate soy products (Bishop et al., 1990). Moreover, although formulas based on hydrolyzed proteins from $\mathrm{CM}$ are usually well tolerated by children and infants, the process may give rise to new antigen peptides (Halken et al., 1993), producing other problems (Stanley and Bannon, 2003).

Another alternative, for cases in which CMPA is observed, is to replace CM with goat milk (GM). A report by the European Commission in 1991 recommended the use of this milk for children having a risk of allergies, as well as for those who are hypersensitive to protein in the diet. Allergy to GM has been reported only rarely and, in general, is ascribed to adulteration of GM with CM. Park (1994) highlighted the importance of this possibility for patients with CMPA, recommending it on the grounds that, in his opinion, tolerance is practically $100 \%$ among such patients. Restani (2004) observed that GM seems to be less allergenic than CM, but also cited various cases in which people of different ages had suffered an allergic reaction after consuming either GM or products derived from it.

On the basis of experiments carried out on guinea pigs, Bevilacqua et al. (2001) drew attention to the need to take into account the high degree of genetic polymorphism among goats, in relation to the content of $\alpha_{\mathrm{S} 1}-\mathrm{CN}$ in GM. According to these authors, GM should be considered hypoallergenic with respect to $\mathrm{CM}$ only when low levels of $\alpha_{\mathrm{S1}^{-}} \mathrm{CN}$ are present. However, Lara-Villoslada et al. (2004) performed studies of atopy in mice, sensitizing the animals with whole GM, with no type of restriction on its composition, and CM. 
Table 1. Protein fraction composition (g/100 g of total protein) of goat milk (GM), cow milk (CM), goat milk lactoserum (GML), and cow milk lactoserum (CML)

\begin{tabular}{|c|c|c|c|c|}
\hline Item & GM & $\mathrm{CM}$ & GML & CML \\
\hline Total CN & 81.7 & 82.0 & - & - \\
\hline Total lactoserum proteins & 18.3 & 18.0 & 100.0 & 100.0 \\
\hline$\alpha_{\mathrm{S}^{-}} \mathrm{CN}$ & 16.9 & 32.6 & - & - \\
\hline$\alpha_{\mathrm{S} 2}-\mathrm{CN}$ & 11.5 & 8.5 & - & - \\
\hline$\beta-\mathrm{CN}$ & 47.4 & 30.2 & - & - \\
\hline$\kappa-\mathrm{CN}$ & 5.9 & 10.7 & - & - \\
\hline Serum albumin & 2.3 & 1.5 & 12.6 & 8.3 \\
\hline$\alpha-\mathrm{LA}$ & 5.5 & 6.4 & 30.0 & 35.4 \\
\hline$\beta-\mathrm{LG}$ & 10.5 & 10.1 & 57.4 & 56.3 \\
\hline
\end{tabular}

The results obtained suggest that GM is hypoallergenic compared with CM.

Taking into account this background, the object of this study was to determine whether GM could be an alternative to CM in cases where CMPA occurs and whether this allergenicity is caused by $\mathrm{CN}$ or by lactoserum proteins. No study has previously been published describing a comparative analysis, using both in vivo and in vitro assays, of allergenicity to whole GM and $\mathrm{CM}$ and their respective lactosera. A further aim is to identify the target molecules against which the antibodies are aimed.

\section{MATERIALS AND METHODS}

\section{Milk and Lactoserum Proteins}

The GM was derived from Granadina goats and the CM from Holstein-Friesian cows. Lactosera were prepared from skim milk. Goat milk lactoserum (GML) was prepared by isoelectric precipitation at $\mathrm{pH} 4.1$ (Recio et al., 1997) and cow milk lactoserum (CML) by precipitation at $\mathrm{pH} 4.6$ (Van Hekken and Thompson, 1992). Table 1 shows the fractional composition of the GM and CM used, and the corresponding lactosera, as determined by the near-infrared spectroscopy methodology (Burns and Ciurczak, 2001; Gómez-Ruiz et al., 2004). For all the solutions, the protein concentration was determined by the bicinchonic acid method, obtaining aliquots that were subsequently stored at $-80^{\circ} \mathrm{C}$ until required. The polypeptide pattern of these solutions was obtained by SDS electrophoresis on polyacrylamide gels stained with Coomassie R-250 blue (Bio-Rad Laboratories, Hercules, CA). Six micrograms of protein per lane from each solution was used, the proteins being separated in 17\% reducing SDS polyacrylamide gels. A previously stained molecular weight marker (Bio-Rad) was included in the first lane. The second lane was reserved for goat $\beta$-CN isolated by HPLC, provided by Technical Services at Granada University, Spain. The third lane was loaded with rabbit $\operatorname{IgG}\left(\mathrm{H}^{+} \mathrm{L}\right.$; Serotec Ltd., Oxford, UK).

\section{In Vivo Assay: Animals and Experimental Protocol}

The animals used throughout this study were 128 male Dunkin Harley guinea pigs with a mean BW of $220.0 \mathrm{~g}$ at weaning, and free from specific pathogens including ecto- and endoparasites (Harlan Ibérica, Barcelona, Spain). The animals were housed individually in stainless steel wire-bottomed cages in climatic chambers maintained under controlled conditions $\left(21-24^{\circ} \mathrm{C}\right.$, $50-60 \%$ relative humidity, diurnal light cycle of $12 \mathrm{~h}$ ). Four in vivo allergenicity assays were carried out, in each of which 32 animals $(\mathrm{n}=4)$ were used.

Assay 1. Systemic Anaphylaxis: GM and CM. Four groups of 8 guinea pigs were used. Two groups were used for oral sensitization to GM or CM proteins (groups 2 and 4, respectively). The other 2 groups (1 and 3) were the corresponding controls. All animals were given a standard diet free from milk proteins (Harlan Ibérica) and water was available. In addition, the following test products were given in liquid form: GM and CM, each with a milk protein content of 32.6 $\mathrm{g} / \mathrm{L}$. For both types of milk, protein concentrations were equalized by diluting, as necessary, the milk presenting the greater concentration. The standard diet, water, and milk were administered ad libitum.

Milk was provided for $15 \mathrm{~d}$; then, from d 16 to 22, the animals were given only water to drink. Finally, at $22 \mathrm{~d}$ the intravenous challenge for systemic anaphylaxis was performed. Each animal in groups 1 and 2 was injected with $0.5 \mathrm{~mL}$ of GM in the anterior saphenous vein, and those in groups 3 and 4 were given $0.5 \mathrm{~mL}$ of $\mathrm{CM}$ by the same method. The animals were observed to determine in which cases lethal anaphylaxis occurred. Serum samples were taken from the orbital sinus of experimental animals at 0 and $22 \mathrm{~d}$ after initiating the experiment to perform the passive cutaneous anaphylaxis (PCA) tests, and to carry out the serological study.

Assay 2. Systemic Anaphylaxis: GML and $\boldsymbol{C M L}$. This assay was carried out using the same experimental design as the previous one, but in this case, GML and CML solutions were used for oral sensitization and for the intravenous antigen challenge. The lac- 
toserum protein content was $7.9 \mathrm{~g} / \mathrm{L}$. For both types of lactoserum, the protein concentrations were equalized by diluting, as necessary, the lactoserum presenting the greater concentration.

Assay 3. PCA: GM and CM. Four groups of 8 guinea pigs were used. The animals in groups 2 and 4 were intradermally injected into the shaven back with $0.1 \mathrm{~mL}$ (diluted 1:2) of a pool of sera from the animals that had suffered lethal anaphylaxis in assay 1 . Twentyfour hours later, the animals were challenged by intravenous injection of $0.5 \mathrm{~mL}$ of the same test solutions used for systemic anaphylaxis (GM for group 2 and CM for group 4), in $2 \%$ Evans Blue (Sigma-Aldrich, St. Louis, MO). Thirty minutes after challenge, the animals were anesthetized by intraperitoneal administration of sodium pentothal (B. Braun Medical S.A., Rubi, Barcelona, Spain). The extent of extravasation of the dye was determined on the back of the skin with the aid of a ruler; PCA reactions with blueing of $>0.5$ $\mathrm{cm}$ in diameter were defined as positive (Pahud et al., 1985). The control animals (groups 1 and 3) were injected with PBS into the shaven back, and the antigen challenge was performed with GM and CM.

Assay 4. PCA: GML and CML. This assay was carried out under the same protocol as for assay 3 , but in this case, the serum pool utilized for passive sensitization was obtained from the animals that had suffered anaphylactic shock in assay 2; the antigen challenge was carried out with GML for groups 1 and 2, and with CML for groups 3 and 4 .

All work was carried out following European Union and Spanish rules and guidelines regarding the ethical treatment of laboratory animals.

\section{In Vitro Assay: Systemic Antibodies}

ELISA Test. The specific antibodies [IgG1 and $\operatorname{IgG}(\mathrm{Fc})]$ against $\mathrm{GM}, \mathrm{CM}$, and their respective lactosera were detected by a modified ELISA technique (Gómez García et al., 2003). The plates with capacity of 100 $\mu \mathrm{L} /$ well (Nunc MaxiSorp Surface, Roskilde, Denmark) were coated with $0.05 \mu \mathrm{g} / \mu \mathrm{L}$ of GM, CM, GML, and CML, in $0.1 M$ carbonate buffer ( $\mathrm{pH} 9.6$ ), sealed, and incubated for $30 \mathrm{~min}$ at $37^{\circ} \mathrm{C}$. Unbound antigen was removed by decanting. The plates were washed 3 times for 5 min with wash solution (tap water, $0.05 \%$ Tween 20; Merck, Darmstadt, Germany). This procedure was used between each step. Then, sera samples (1:4 and 2 -fold serial dilutions) were added to the plates, which were sealed and incubated for $30 \mathrm{~min}$ at $37^{\circ} \mathrm{C}$. Guinea pig anti-IgG1 or anti-IgG(Fc) conjugated to peroxidase (Serotec) diluted at 1:5,000 or 1:10,000 respectively, in PBS $/ 0.05 \%$ Tween 20 (Merck), was incubated for $30 \mathrm{~min}$ at $37^{\circ} \mathrm{C}$. The plates were developed by $\mathrm{H}_{2} \mathrm{O}_{2}$ as substrate and by chromogen 2,2'-azino-bis (3 ethylbenzyl-thiazoline-6-sulfonic acid) (Sigma-Aldrich), and kept for $15 \mathrm{~min}$ at room temperature in the dark. The reaction was stopped with 1\% SDS (Merck). The plates were read at $405 \mathrm{~nm}$ in a Bio-Rad Microplate Manager, version 4.0. A limiting optical density (OD) value was calculated by adding to the mean of the OD values of 3 replicates of sera from $d 0$ of each animal, the results of multiplying the standard deviation by 3 . The OD values above this cut-off value were considered positive.

The OD values obtained from the 3 replicates for each serum at the 1:64 dilution were used to determine, statistically, the possible differences in the production of systemic antibodies, with respect to the different immunizing solutions.

Western Blot Test. This test was applied to detect and identify the different antibodies developed against GM, CM, GML, and CML in guinea pigs after oral immunization. Forty micrograms of protein per lane from each solution was used. The protein was separated in $17 \%$ reducing SDS polyacrylamide gels (Bio-Rad). After electrophoresis $\left(400 \mathrm{~V}\right.$ at $\left.4^{\circ} \mathrm{C}\right)$, the proteins were transferred to nitrocellulose sheets (Protran Ba 85, 0.45 $\mu \mathrm{m}$, Whatman GmbH, Dassel, Germany) in a Mini Trans Blot cell (Bio-Rad) and maintained for $12 \mathrm{~h}$ at $30 \mathrm{~V}$ and $4^{\circ} \mathrm{C}$. After transfer, the membrane was rinsed 3 times ( 5 min each). This procedure was used between each step. Strips $0.4 \mathrm{~mm}$ thick were cut and incubated with a 1:10 dilution of guinea pig serum in PBS/0.3\% Tween-20 (Merck) for $1 \mathrm{~h}$. After washes in PBS/0.3\% Tween-20 (Merck), a 1:500 or 1:1,000 dilution of a goat anti-guinea pig IgG1 or $\operatorname{IgG}(\mathrm{Fc})$ peroxidase conjugate (Serotec), respectively, in PBS/0.3\% Tween-20 (Merck) was added for $1 \mathrm{~h}$. After another washing cycle, peroxidase was developed with hydrogen peroxide (SigmaAldrich) and 4-chloro-1-naphthol (Sigma-Aldrich). A prestained molecular weight marker (precision plus protein standards; Bio-Rad) and caprine $\beta-\mathrm{CN}$ isolated by HPLC (Technical Services, Granada University, Spain) were included. The antigen patterns obtained were analyzed using Quantity One 4.4.0 program (Bio-Rad).

The cross-reactivity among the milk proteins and that of their respective lactosera, were determined by blotting, following the protocol described above. After the electrotransfer of GM and CM had been performed, they were tested against the sera from the animals immunized with CM and GM, respectively. The same procedure was followed for the lactosera.

\section{Statistical Analysis}

A classical 2-proportions comparison test (Sokal and Rohlf, 1979) was applied to the results of the systemic anaphylaxis and PCA assays. In the serological tests, 
the differences between mean $\mathrm{OD}$ values at the 1:64 dilution were assessed by ANOVA. Statistical analyses were performed using the Statgraphics statistical package (Statgraphics, 2001). Duncan's test $(P<0.05)$ was used to determine the differences between the means.

\section{RESULTS}

\section{Protein Fraction Composition and Polypeptide Profile of GM, CM, GML, and CML}

Table 1 shows the protein fraction composition of the GM and CM and of their respective lactosera. In this respect, the 2 types of milk differed; GM presented lower quantities of $\alpha_{S^{-}} \mathrm{CN}$ and $\kappa$-CN, and greater quantities of $\beta$-CN and seroalbumin. The composition of the 2 lactosera varied less, and CN was notably absent.

Figure 1 shows the polypeptide profile obtained after electrophoresis and staining. The apparent molecular weights of the majority polypeptides were as follows: lane 1 , molecular weight markers, range 10 to $100 \mathrm{kDa}$; lane 2 , one band corresponding to the $\beta-\mathrm{CN}$, about 25 $\mathrm{kDa}$; lane 3 shows 2 majority bands in the region of 24 to $55 \mathrm{kDa}$, which correspond to the light- and heavychain immunoglobulins, respectively; lane 4 (GM) shows 3 minority bands with apparent sizes of 84,64 , and 55 $\mathrm{kDa}$ that correspond to lactoferrin, seroalbumin, and to heavy-chain IgG. The region between 27 and $24 \mathrm{kDa}$ corresponds to the $\mathrm{CN}$ complex and to the light-chain IgG. Finally, there are 2 polypeptides of low molecular weight, 17 and $13 \mathrm{kDa}$, which correspond to $\beta-\mathrm{LG}$ and $\alpha$-LA, respectively, the latter in its 2 isoforms, normal and glycosylate. In lane $5(\mathrm{CM})$, in general, the same polypeptide profile was obtained as with GM. The electrophoretic profile in lanes 6 and 7 (GML and CML, respectively) showed the 3 bands of high molecular weight that correspond to lactoferrin, seroalbumin, and heavy-chain $\operatorname{IgG}$, followed by a band at about $24 \mathrm{kDa}$, which corresponds to light-chain $\operatorname{IgG}$, together with the 2 bands of low molecular weight, representing $\beta-\mathrm{LG}$ and $\alpha$-LA. The latter were found to have increased to a greater degree, quantitatively, in the lactosera than in the 2 types of milk, because in the $6 \mu \mathrm{g}$ of protein content deposited in each lane, its relative proportion was greater among the lactosera.

\section{In Vivo Assays: Systemic Anaphylaxis and PCA}

The nutritional response of the guinea pigs in the different assays was satisfactory, and there were no significant differences in the weights of the animals in the different groups by the end of the assays, or in the consumption of the corresponding immunizing solutions (data not shown here).

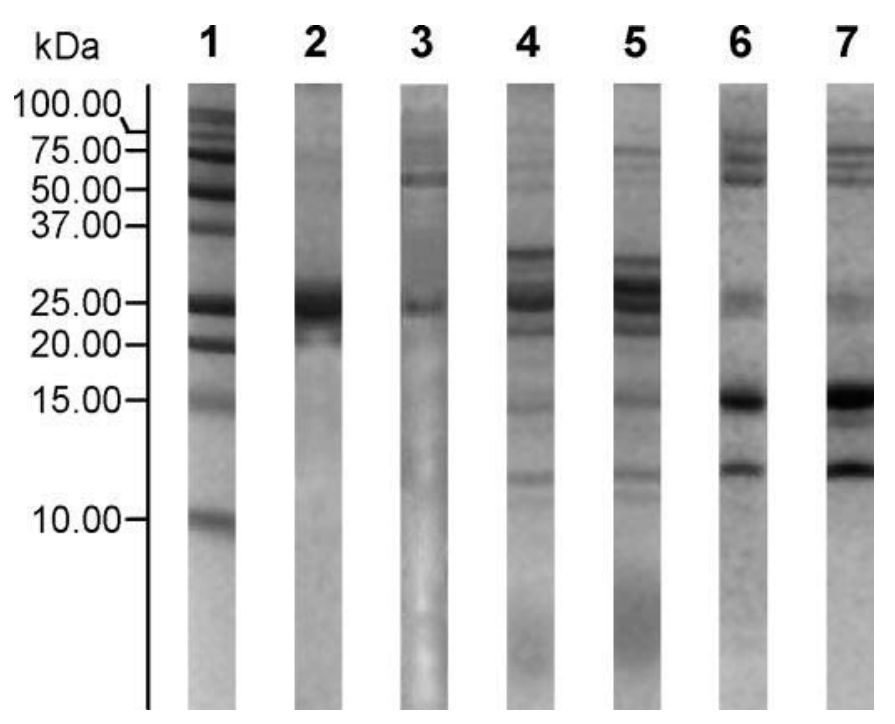

Figure 1. Sodium dodecyl sulfate-PAGE pattern of goat and cow milk and their respective lactosera. Lane $1=$ prestained molecular weight marker (Bio-Rad, Hercules, CA); lane $2=$ goat $\beta$-casein marker isolated by Technical Services (Granada University, Spain); lane $3=$ rabbit IgG marker (Serotec, Oxford, UK); lane $4=$ goat milk (GM); lane $5=$ cow milk (CM); lane $6=$ goat milk lactoserum (GML); and lane $7=$ cow milk lactoserum (CML).

Table 2 shows the results of the systemic anaphylaxis test and of the statistical analysis performed. A trend was observed for the response to be greater for CM vs. GM $(P<0.20)$, for CML vs. GML $(P<0.10)$, and for each type of milk vs. its respective lactoserum (GM vs. GML, $P<0.10$, and CM vs. CML, $P<0.20$ ). Table 3 shows the results of the PCA test and the statistical analysis performed. For the animals that were passively immunized against GM and CM, the number of positive reactions was identical. On comparing this with the case of the 2 types of lactosera, there were seen to be fewer positive responses $(P<0.10)$ among the animals that were passively immunized against GML. Moreover, concerning the results for each type of milk vs. its corresponding lactoserum, the response values were lower when the animals had been passively immunized against each type of milk (GM vs. GML, $P<$ 0.20 ; CM vs. CML, $P<0.05)$. All the control animals tested negatively in both the systemic anaphylaxis assay and in the PCA.

\section{In Vitro Assay: Systemic Antibodies}

ELISA Test. The levels of specific $\operatorname{IgG} 1$ and $\operatorname{IgG}(\mathrm{Fc})$ against the various antigen solutions were measured using ELISA. Serum samples with OD above the cut-off value were considered positive. For the $\operatorname{IgG}(\mathrm{Fc})$ isotype, all the serum samples from the experimental animals were found to have specific antibodies against GM and 
Table 2. Statistical analysis results for animals with fatal systemic anaphylaxis (assays 1 and 2 ; total $\mathrm{n}=8 \times 4=32$ )

\begin{tabular}{lllcl}
\hline $\begin{array}{l}\text { Antigenic solution used } \\
\text { for oral sensitization }^{1}\end{array}$ & $\begin{array}{l}\text { Antigenic solution used } \\
\text { for intravenous challenge }\end{array}$ & $\mathrm{n}$ & $\begin{array}{c}\text { Fatal } \\
\text { anaphylaxis (\%) }^{1}\end{array}$ & Contrast $^{2}$ \\
\hline GM & GM & 8 & 50.0 & GM + GM vs. CM + CM \\
CM & GM & 8 & 75.0 & GML + GML vs. CML + CML $\quad<0.10$ \\
GML & GML & 8 & 12.5 & GM + GM vs. GML + GML $<\quad<0.10$ \\
CML & GML & 8 & 50.0 & CM + CM vs. CML + CML \\
\hline
\end{tabular}

${ }^{1} \mathrm{GM}=$ goat milk, $\mathrm{CM}=$ cow milk, GML = goat milk lactoserum, $\mathrm{CML}=$ cow milk lactoserum.

${ }^{2} \mathrm{GM}+\mathrm{GM}=\mathrm{GM}$ used for oral sensitization and for intravenous challenge, $\mathrm{CM}+\mathrm{CM}=\mathrm{CM}$ used for oral sensitization and for intravenous challenge, GML + GML $=$ GML used for oral sensitization and for intravenous challenge, CML + CML $=$ CML used for oral sensitization and for intravenous challenge.

CM. For the subclass IgG1, 6 animals were positive against GM and 8 against CM. In all cases, the lactosera presented antibodies for the class and subclass of immunoglobulin considered. In the sera of the control animals in each assay, the reaction was negative. Figures 2 and 3 show the mean OD values of specific IgG1 and $\operatorname{IgG}(\mathrm{Fc})$ in the animals sensitized orally to GM, CM, GML, and CML. It can be seen that the production of specific antibodies for the $\operatorname{IgG1}$ and $\operatorname{IgG}(\mathrm{Fc})$ isotypes was greater among the animals given $\mathrm{CM}$ than among those given GM. In the animals given CML and GML, the antibody response was lower and, at the same time, more closely grouped; in these cases, the animals remained positive at higher titers than those corresponding to the 2 types of milk.

Tables 4 and 5 present, together with the cut-off values, the $\mathrm{OD}$ values corresponding to the 1:64 dilution for the specific antibodies of the IgG1 subclass and the $\operatorname{IgG}(\mathrm{Fc})$ class, together with the results from the statistical analysis performed. The chosen dilution may be considered, depending on the case, as a medium dilution. For both isotypes, the values corresponding to the animals given $\mathrm{CM}$ were greater than for those given GM, with the corresponding differences presenting a level of significance of $P<0.10$ for IgG1 and of $P<$ 0.05 for $\operatorname{IgG}(\mathrm{Fc})$. As before, the values for the animals immunized with each type of milk were greater than those obtained for the lactosera, with these differences being statistically significant in the case of the $\operatorname{IgG}(\mathrm{Fc})$ isotype $(P<0.05)$. On the contrary, for the IgG1 isotype, the difference was only statistically significant $(P$ $<0.05$ ) in the comparison of the values for CM vs. CML. For both isotypes, the values for the corresponding lactosera were very similar $(P>0.05)$.

Western Blot Test. Figure 4 shows the antigen polypeptide profile of the 2 milk types and the corresponding lactosera. In lanes 1 and 2, the electrophoretic bands correspond to markers of molecular weights and GM $\beta$-CN, respectively, whereas in lanes $3,4,5$, and 6 , they refer to GM, CM, GML, and CML.

In general, the antibodies of the subclass IgG1 response were aimed at polypeptides with apparent molecular weights ranging from 75 to $13 \mathrm{kDa}$. This antigenic profile matches the polypeptide profile illustrated in Figure 1; note that in the region of high molecular weight there are 2 bands corresponding to the sera of the animals that were sensitized with GM and CM. In the latter case, the band corresponding to $\alpha-\mathrm{LA}$ is either fainter or is not distinguished. With respect to the animals sensitized to GML and CML, antibodies were detected to light and heavy-chain immunoglobulins, $\beta-\mathrm{LG}$, and $\alpha-\mathrm{LA}$. As expected, the band corresponding

Table 3. Statistical analysis results for animals with positive response to passive cutaneous anaphylaxis (assays 3 and 4 ; total $\mathrm{n}=8 \times 4=$ 32)

\begin{tabular}{|c|c|c|c|c|c|}
\hline Donor antibody ${ }^{1}$ & $\begin{array}{l}\text { Antigenic solution used } \\
\text { for intravenous challenge }\end{array}$ & $\mathrm{n}$ & $\begin{array}{c}\text { Positive } \\
\text { response (\%) }\end{array}$ & Contrast $^{3}$ & $P$-value \\
\hline Ab-GM & GM & 8 & 75.0 & Ab-GM + GM vs. Ab-CM + CM & $>0.05$ \\
\hline $\mathrm{Ab}-\mathrm{CM}$ & $\mathrm{CM}$ & 8 & 75.0 & Ab-GML + GML vs. Ab-CML + CML & $<0.10$ \\
\hline $\mathrm{Ab}-\mathrm{CML}$ & CML & 8 & 100.0 & $\mathrm{Ab}-\mathrm{CM}+\mathrm{CM}$ vs. Ab-CML + CML & $<0.05$ \\
\hline
\end{tabular}




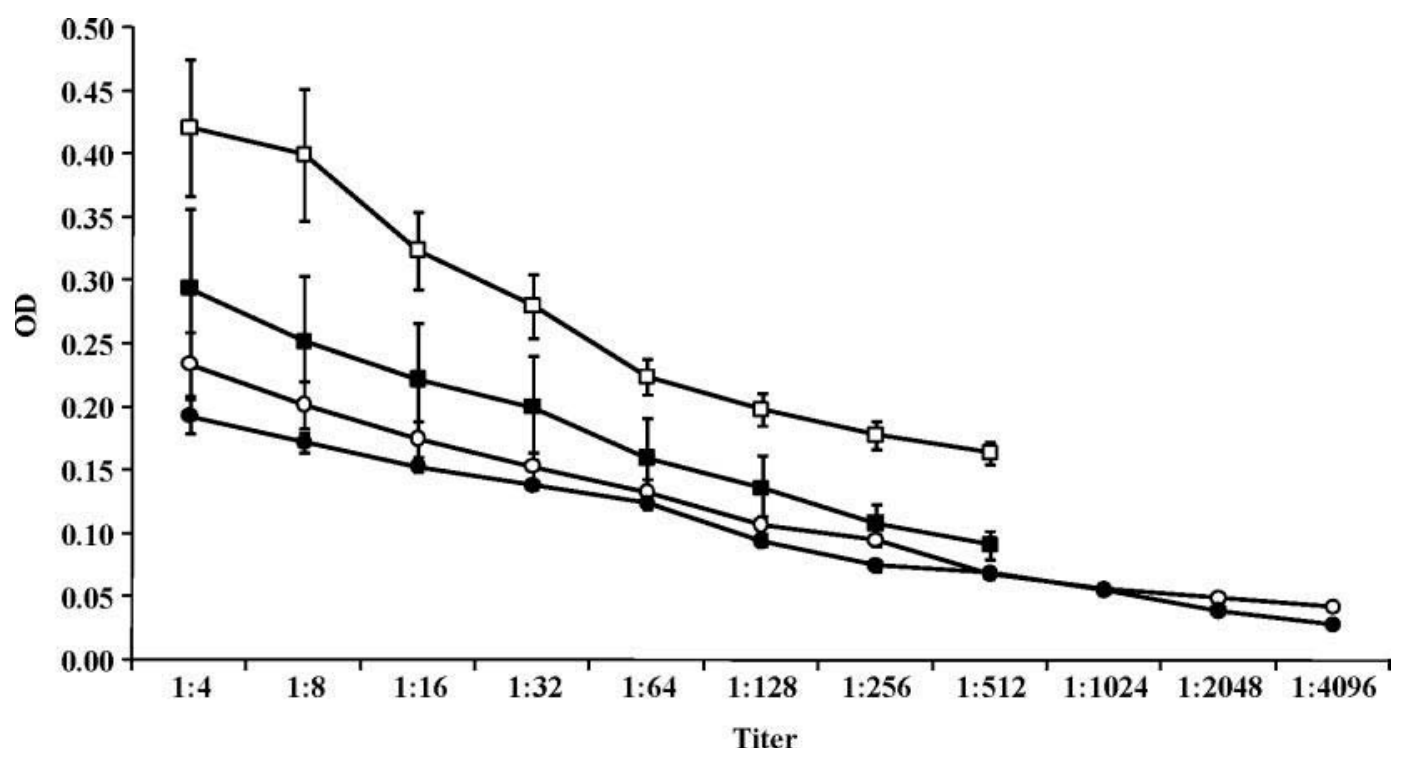

Figure 2. Mean ( $\pm \mathrm{SE}$ ) of the optical density $(\mathrm{OD})$ values of specific IgG1 in animals sensitized by oral route to goat milk (GM, $\mathbf{\square})$, cow milk (CM, $\square$ ), goat milk lactoserum (GML, $\bullet$ ), and cow milk lactoserum (CML, $\bigcirc)$.

to the CN complex was not observed. This is because these proteins are not present in the lactosera, and antibodies against them have not been formed. Moreover, the images of the bands corresponding to $\beta-L G$ and $\alpha$-LA are more intense, because in the $40 \mu \mathrm{g}$ of proteins introduced into the samples, the quantity of serum proteins was greater due to the absence of CN. A similar, although somewhat weaker, pattern was recorded for the $\operatorname{IgG}(\mathrm{Fc})$ immunoglobulins. The sera from $\mathrm{d} 0$ for each animal showed no bands.
The cross reactivity among the GM and CM proteins, as determined by Western blotting, is shown in Figure 5. The only secondary antibody used was guinea pig anti-IgG1 marked with peroxidase, because in the specific detection test for IgG1 and $\operatorname{IgG}(\mathrm{Fc})$, the same antigen pattern was obtained. The sera from the animals that were sensitized to GM presented the same antigen pattern in CM and GM electrophoretic separation. The same was true for the sera of the animals sensitized to CM between the 2 types of lactoserum.

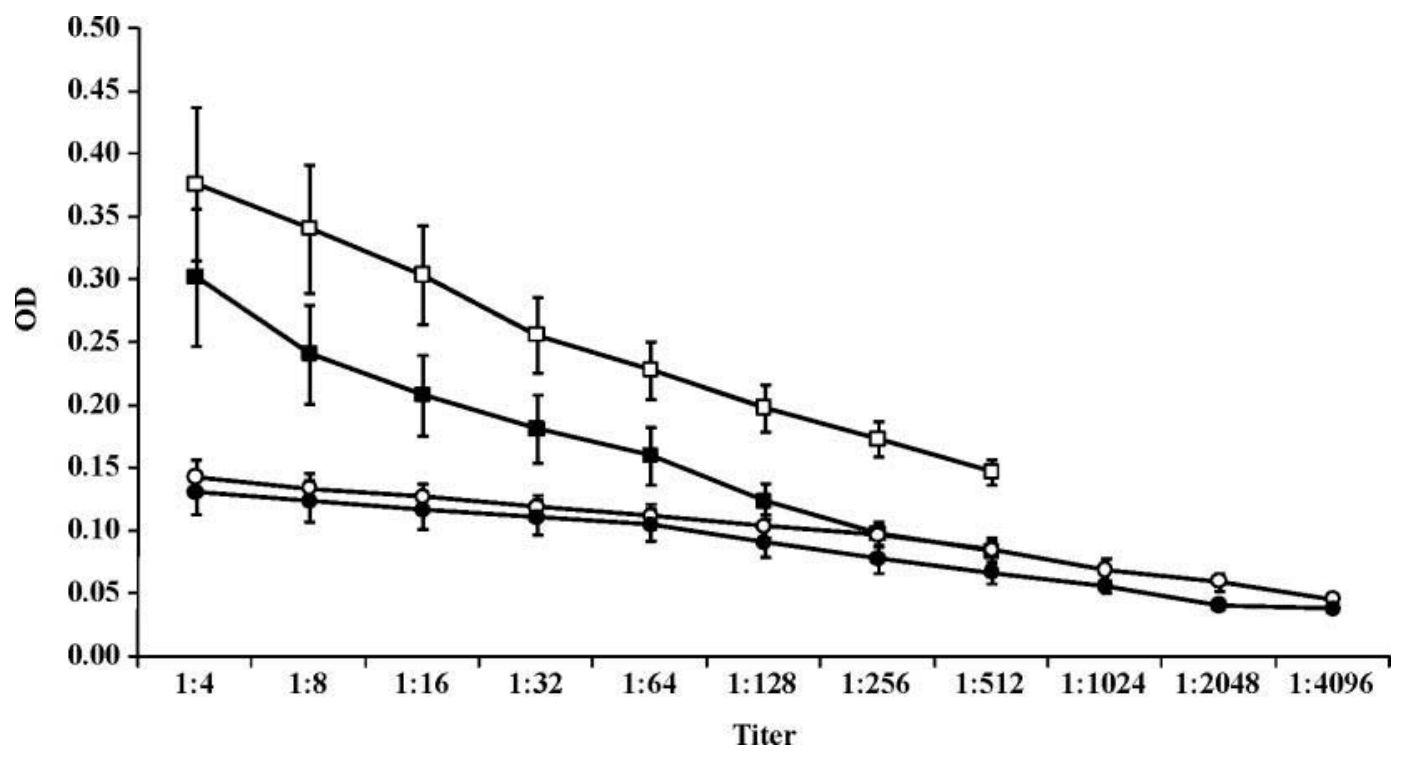

Figure 3. Mean $( \pm \mathrm{SE})$ of the optical density $(\mathrm{OD})$ values of specific $\operatorname{IgG}(\mathrm{Fc})$ in animals sensitized by oral route to goat milk (GM, $\mathbf{\square})$, cow milk (CM, $\square$ ), goat milk lactoserum (GML, $\bullet$ ), and cow milk lactoserum (CML, $\bigcirc)$. 


\section{DISCUSSION}

This is the first comparative study of the allergenicity of GM and CM, and of their respective lactosera (in vivo assays), together with a serologic study using ELISA and the Western blotting (in vitro assays). Particularly notable is the utilization of the lactosera, because of the current controversy as to whether $\mathrm{CN}$ is capable of producing antibodies when ingested orally.

The protein composition detected for the 2 types of milk and their respective lactosera was similar to that described in the literature (Haenlein, 2004). Sodium dodecyl sulfate was used as the denaturing agent for the electrophoretic separation of the polypeptides in the antigen solutions. This was necessary because of the complex nature of the milk, the constituents of which are partly in suspension and partly in solution, which makes their separation unsatisfactory under nondenaturing conditions (Restani et al., 2002). The polypeptide profile obtained for the protein components of GM, CM, GML, and CML was similar to that described in the literature (Kim and Jiménez-Flores, 1994).

\section{In Vivo Assays: Systemic Anaphylaxis and PCA}

The guinea pig is an experimental model that has been amply used in type I allergenicity assays. It was first described by Parish et al. (1964) as election model due to its high sensibility for studying CMPA, and it has been widely used for allergy assays with milk formulas (McLaughlan et al., 1981). Other animal models (rats, mice) have been employed, but despite being less expensive, they have also proved to be less sensitive (Lara-Villoslada et al., 2005)

The results obtained from the systemic anaphylaxis test show GM to be hypoallergenic with respect to CM, as is each lactoserum with respect to the corresponding milk, especially in the case of GML. Therefore, CN seems to contribute to the systemic anaphylaxis reaction detected in each case. The fact that the weakest reaction corresponded to GML could mean that the lower allergenicity of GM vs. CM is due to the fact that

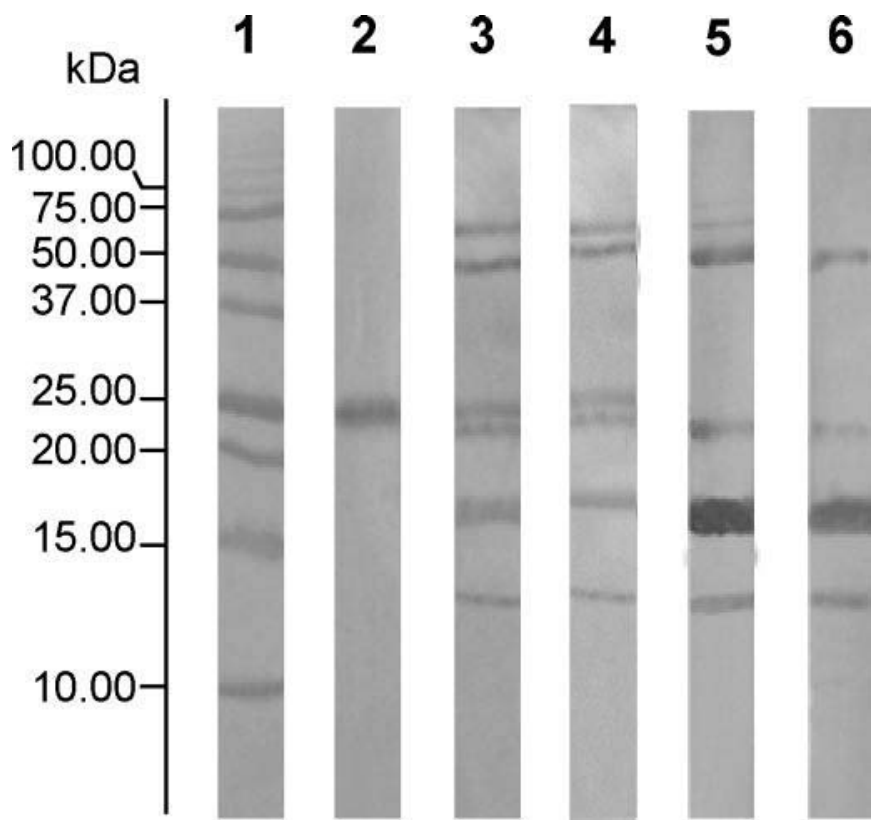

Figure 4. Western blot developed against the sera of animals used for the systemic anaphylaxis assay, sensitized to goat milk (GM) and cow milk $(\mathrm{CM})$. Lane $1=$ prestained molecular weight marker (BioRad, Hercules, CA); lane $2=\beta$-casein from GM, isolated by Technical Services (Granada University, Spain) and incubated with antibodies against GM; lane $3=\mathrm{GM}$ proteins subjected to electrophoresis and incubated with antibodies against GM; lane $4=\mathrm{CM}$ proteins subjected to electrophoresis and incubated with antibodies against CM; lane 5 $=$ goat milk lactoserum (GML) proteins subjected to electrophoresis and incubated with antibodies against GML; and lane $6=$ cow milk lactoserum (CML) proteins subjected to electrophoresis and incubated with antibodies against CML.

GML proteins are especially hypoallergenic. Bevilacqua et al. (2001) studied guinea pigs immunized orally with 2 types of GM, differentiated by their $\alpha_{\mathrm{S}_{1}} \mathrm{CN}$ content, and CM. After provoking intestinal anaphylaxis in vitro, the authors concluded that the response to certain milk proteins is greater among animals sensitized with CM than with GM. Lara-Villoslada et al. (2004) performed atopy studies with mice, and concluded, likewise, that $\mathrm{CM}$ is more allergenic than GM.

Table 4. Mean optical density (OD) values of specific IgG1 obtained by ELISA in the serum of animals immunized per os against the different antigenic solutions (total $\mathrm{n}=8 \times 4=32$ )

\begin{tabular}{lllllcc}
\hline Specific IgG1 & Cut-off value & $\mathrm{n}$ & $\mathrm{OD}^{2}$ & Contrast & RSD $^{3}$ & $P$-value \\
\hline IgG1 GM & OD $=0.141$ & 8 & 0.160 & IgG1 GM vs. IgG1 CM & 0.069 & $<0.10$ \\
IgG1 CM & OD $=0.157$ & 8 & 0.224 & IgG1 GML vs. IgG1 CML & 0.021 & $>0.05$ \\
IgG1 GML & OD $=0.052$ & 8 & 0.124 & IgG1 GM vs. IgG1 GML & 0.063 & $>0.05$ \\
IgG1 CML & OD $=0.038$ & 8 & 0.133 & IgG1 CM vs. IgG1 CML & 0.034 & $<0.001$ \\
\hline
\end{tabular}

${ }^{1} \mathrm{IgG1GM}=$ antibody against goat milk; IgG1 CM = antibody against cow milk; IgG1 GML = antibody against goat milk lactoserum; IgG1 CML = antibody against cow milk lactoserum.

${ }^{2}$ Sera dilution 1:64.

${ }^{3} \mathrm{RSD}=$ residual standard deviation. 


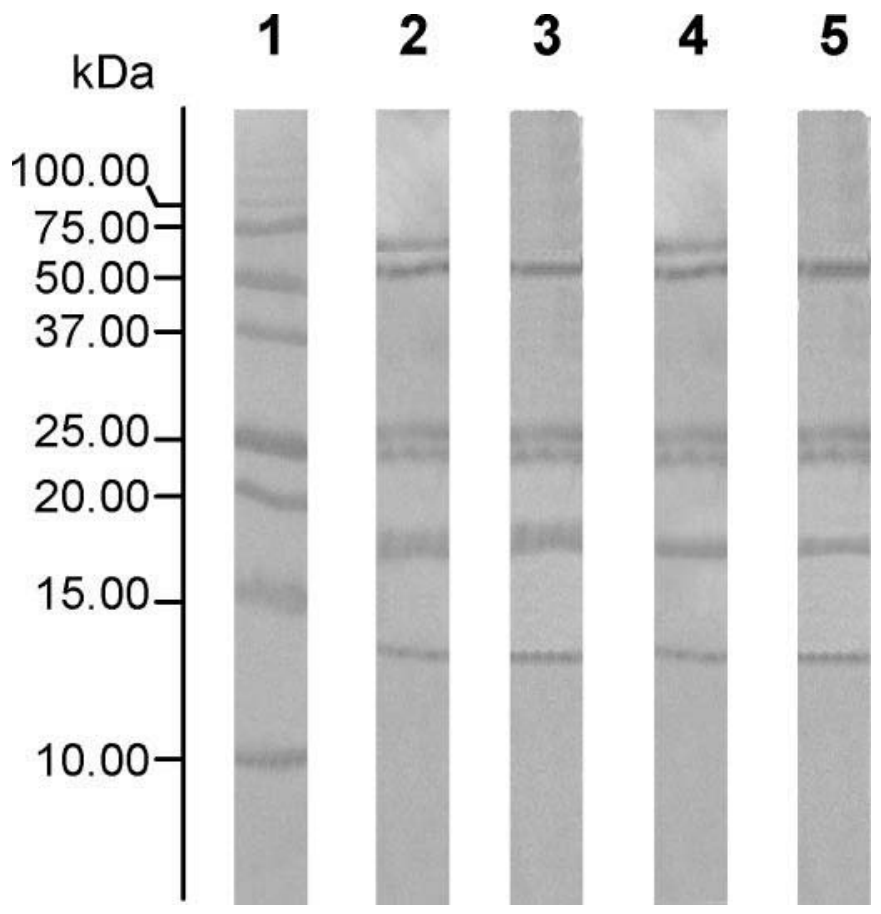

Figure 5. Western blot developed against the sera of animals used for the systemic anaphylaxis assay, sensitized to goat milk (GM) and cow milk $(\mathrm{CM})$. Lane 1 = prestained molecular weight marker (BioRad, Hercules, CA); lane $2=$ GM proteins subjected to electrophoresis and incubated with antibodies against GM; lane $3=\mathrm{CM}$ proteins subjected to electrophoresis and incubated with antibodies against GM; lane $4=\mathrm{CM}$ proteins subjected to electrophoresis and incubated with antibodies against $\mathrm{CM}$; and lane $5=\mathrm{GM}$ proteins subjected to electrophoresis and incubated with antibodies against CM.

In the present study, the number of passively sensitized animals (PCA) was identical for the 2 types of milk, although the reactions to CM were more intense. In a study of humans, Perlman (1977) reported that a greater number of positive cutaneous tests were obtained with CM than with GM proteins. The lactosera produced a greater number of positive reactions than did the 2 types of milk (earlier studies do not seem to have addressed this question). This could be caused by the greater presence of $\mathrm{IgE}$ in the sera transferred.
Accordingly, infants who are allergic to CM have been found to present greater levels of specific IgE in serum with respect to the lactoserum proteins (Hoffman, 1975), whereas among allergic older children and adults, specific $\operatorname{IgE}$ is a majority component with respect to the CN fraction (Docena et al., 1996). For well-characterized extracts, Martín Esteban et al. (1999) reported that the positive predictive value of cutaneous tests is below $50 \%$. Therefore, a positive reaction does not necessarily mean that the patient will develop clinical symptoms of an allergy. Moreover, among children who have developed tolerance, reactivity to the cutaneous test persists (i.e., there are false positives; David et al., 1999). Despite the low predictive value of a positive reaction, a negative result rules out a food-based reaction mediated by IgE (Bruijnzeel-Koomen et al., 1995).

\section{In Vitro Assay: Systemic Antibodies}

ELISA Test. It has been shown that IgE antibodies play an important role in mediating type I hypersensitivity responses in humans. In food allergy, it is believed that food-specific IgE antibodies bind to high-affinity Fc $\varepsilon$ RI receptors on mast cells, basophils, macrophages, and dendritic cells, as well as to low-affinity Fce RII receptors on macrophages, monocytes, lymphocytes, eosinophils, and platelets (Sampson and Ho, 1997). When food allergens penetrate mucosal barriers and contact IgE antibodies bound to mast cells or basophils, histamine and other mediators that induce symptoms of immediate hypersensitivity are released.

Various researchers have found in experiments with guinea pigs that in hypersensitivity reactions mediated by IgE, reaginic IgG1 antibodies are also present, both in PCA reactions (Ovary and Warner, 1972) and in those of systemic anaphylaxis (Bevilacqua et al., 2001). As IgG1 and $\operatorname{IgG}(\mathrm{Fc})$ isotypes are present in these kinds of reactions, and because their systemic level is greater than that of the $\operatorname{IgE}$, which makes their detection in serum more feasible, in this study the levels of these 2 isotypes were measured against antigen solutions, using

Table 5. Mean optical density (OD) values of specific $\operatorname{IgG}(\mathrm{Fc})$ obtained by ELISA in the serum of animals immunized per os against the different antigenic solutions (total $\mathrm{n}=8 \times 4=32$ )

\begin{tabular}{lllllcc}
\hline Specific IgG(Fc) & Cut-off value & $\mathrm{n}$ & $\mathrm{OD}^{2}$ & Contrast & RSD $^{3}$ & $P$-value \\
\hline IgG(Fc) GM & OD $=0.155$ & 8 & 0.160 & IgG(Fc) GM vs. IgG(Fc) CM & 0.063 & $<0.05$ \\
IgG(Fc) CM & OD $=0.142$ & 8 & 0.228 & IgG(Fc) GML vs. IgG(Fc) CML & 0.033 & $>0.05$ \\
IgG(Fc) GML & OD $=0.043$ & 8 & 0.105 & IgG(Fc) GM vs. IgG(Fc) GML & 0.051 & $<0.05$ \\
IgG(Fc) CML & OD $=0.048$ & 8 & 0.112 & IgG(Fc) CM vs. IgG(Fc) CML & 0.051 & $<0.001$ \\
\hline
\end{tabular}

${ }^{1} \operatorname{IgG}(\mathrm{Fc}) \mathrm{GM}=$ antibody against goat milk; $\operatorname{IgG}(\mathrm{Fc}) \mathrm{CM}=$ antibody against cow milk; $\operatorname{IgG}(\mathrm{Fc}) \mathrm{GML}=$ antibody against goat milk lactoserum; $\operatorname{IgG}(\mathrm{Fc}) \mathrm{CML}=$ antibody against cow milk lactoserum.

${ }^{2}$ Sera dilution 1:64.

${ }^{3} \mathrm{RSD}=$ residual standard deviation. 
the ELISA technique, for the 2 types of milk and their corresponding lactosera. Lara-Villoslada et al. (2004) reported that antigen-specific IgE levels were too low to be detected.

The present results for GM and CM are in agreement with those obtained by Lara-Villoslada et al. (2004), who reported greater values for specific IgG1 antibodies against CM than against GM. The values for lactosera, however, cannot be compared, as no information is available in the literature on this question. As remarked above with respect to the results for systemic anaphylaxis, the differences observed between milk and lactoserum concerning antibody production again show that $\mathrm{CN}$ contributes to the corresponding allergic reaction. It may be concluded that the largest differences tend to be found between the 2 types of milk, with the values for the 2 lactosera being more closely grouped. Bevilacqua et al. (2001) studied systemic sensitization in guinea pigs against the proteins of CM and GM, and found that the animals that consumed CM proteins developed greater levels of specific antibodies of the IgG1 subclass against $\beta$-LG than did those given GM.

Western Blot Test. The target polypeptides recognized by the serum were detected within a range of 75 to $13 \mathrm{kDa}$ (Figure 4). The sera of the animals immunized with CM recognized the presence of the CN from the GM (Figure 5, lane 5). Note, too, that antibodies were observed to be targeted at the $\mathrm{CN}$, a result that is corroborated by the findings of other authors, who in studies of human sera have detected antibodies against this protein (Muñoz Martín et al., 2004). On the other hand, Bevilacqua et al. (2001), in a study of animals sensitized orally with milk using ELISA and different milk fractions, concluded that the antibodies were targeted at $\beta-\mathrm{LG}$ and $\alpha$-LA.

The Western blot test showed that there is a marked degree of cross-reactivity between the 2 types of milk (Figure 5), and likewise between the 2 types of lactoserum; this result is in agreement with those reported by other authors (Restani et al., 2002). No specific protein in CM was identified as its main allergen. In a recent review of the subject by Wal (2001), it was concluded that no structural or functional characteristic present in any one of the milk proteins could be considered associated with allergenicity, although some homologous regions may account for the IgE type cross-reactivity.

With respect to why GM seems to be hypoallergenic with respect to $\mathrm{CM}$, it has been suggested that in $\mathrm{CM}$ the $\alpha_{S_{1}}-\mathrm{CN}$ could act as a carrier of other allergens, such as $\beta-\mathrm{LG}$, a fraction that would bind to $\alpha_{\mathrm{S} 1}-\mathrm{CN}$ forming a less digestible complex. The GM, which has a lower quantity of $\alpha_{\mathrm{S}_{1}} \mathrm{CN}$, would produce a lower quantity of this complex, thus facilitating the digestion of $\beta-\mathrm{LG}$ (Bevilacqua et al., 2001). In this respect, it is well known that the main factor triggering a nutritional allergic reaction is an increase in the intestinal absorption of antigens, followed by an adverse local immune reaction. Repetitive exposure to CM in cases of allergy to its proteins is associated with an inflammatory response of the lamina propria on the intestinal membrane, together with an increase in macromolecular permeability. In guinea pigs sensitized to milk proteins, Heyman et al. (1990) demonstrated the existence of a greater degree of intestinal permeability to marker macromolecules.

\section{CONCLUSIONS}

Our results lead us to conclude that oral ingestion of the 4 antigen solutions gave rise to systemic sensitization in the animals, and that the sera from these animals, when transferred to healthy specimens, are capable of producing a PCA positive reaction to an antigen challenge. The use of the 2 types of milk and their respective lactosera, as immunizing solutions, showed that milk (especially $\mathrm{CM}$ ) produced a stronger response, whereas the responses following consumption of the lactosera were weaker and more closely grouped. These results show that both $\mathrm{CN}$ and lactoserum proteins may provoke an allergenic response. With respect to the aim of identifying the polypeptides responsible for allergic reactions, these reactions could be due to the existence of specific epitopes present within the different proteins. Therefore, it would be of interest to continue investigating this subject to identify the epitope(s) responsible for the allergenicity; the possibility could then be studied of producing a food that is innocuous to humans with CMPA.

\section{ACKNOWLEDGMENTS}

We are grateful to Vicente Augustín [Instituto de Parasitología y Biomedicina López-Neyra (CSIC), Granada, Spain] for technical assistance. This study was supported financially by the Consejería de Innovación, Ciencia y Empresa, Junta de Andalucía, Spain (project: C03-045).

\section{REFERENCES}

Bevilacqua, C., P. Martin, C. Candalh, J. Fauquant, M. Piot, A. M. Roucayrol, F. Pilla, and M. Heyman. 2001. Goats' milk defective $\alpha_{\mathrm{s} 1}$-casein decreases intestinal and systemic sensitization to $\beta$-lactoglobulin in guinea pigs. J. Dairy Res. 68:217-227.

Bishop, J. M., D. J. Hill, and C. S. Hosking. 1990. Natural history of cow milk allergy: Clinical outcome. J. Pediatr. 116:862-867.

Bruijnzeel-Koomen, C. A. F. M., C. Ortolani, and K. Aas. 1995. Adverse reactions to foods. Position paper. Allergy 50:623-636.

Burns, D. A., and E. W. Ciurczak. 2001. Handbook of Near-Infrared Analysis. Practical Spectroscopy Series. Vol. 27. Marcel Dekker, New York, NY. 
David, T. J., L. Patel, and C. I. Ewing. 1999. Diagnosis and management. Pages 836-843 in Encyclopaedia of Human Nutrition. M. J. Sandler, J. J. Strain, and B. Caballero, ed. Academic Press, London, UK.

Docena, G. H., R. Fernández, F. G. Chirdo, and C. A. Fossati. 1996. Identification of casein as the major allergenic and antigenic protein of cows's milk. Allergy 51:412-416.

Gómez García, V., M. R. Sanz Sampelayo, J. R. Fernández Navarro, F. D. Carmona López, F. Gil Extremera, and M. Rodríguez. 2003. Polyunsaturated fatty acids and parasitism: Effect of a diet supplemented with fish oil on the course of rat trichinellosis. Vet. Parasitol. 117:85-97.

Gómez-Ruiz, J. A., B. Miralles, P. Aguera, and L. Amigo. 2004. Quantitative determination of $\alpha_{\mathrm{S2}^{-}}$and $\alpha_{\mathrm{S}^{-}}$-casein in goat's milk with different genotypes by capillary electrophoresis. J. Chromatogr. A. 1054:279-284.

Haenlein, G. F. W. 2004. Goat milk in human nutrition. Small Rumin. Res. 51:155-163.

Halken, S., A. Host, L. G. Hansen, and O. Osterballe. 1993. Safety of a new, ultrafiltrated hydrolysate whey formula in children with cow milk allergy: A clinical investigation. Pediatr. Allergy Immunol. 4:53-59.

Heyman, M., M. Andriantsoa, A. M. Crain-Denoyelle, and J. F. Desjeux. 1990. Effect of oral and parental sensitization to cow's milk on mucosal permeability in guinea-pigs. Int. Arch. Allergy Immunol. 92:242-246.

Hoffman, D. R. 1975. Food allergy in children: RAST studies with milk and egg. Pages 165-169 in Advances in Diagnosis of Allergy: RAST. R. I. Evans, ed. Stratton, New York, NY.

Kim, H. H., and R. Jiménez Flores. 1994. Comparison of milk protein using preparative isoelectric focusing followed by polyacrylamide gel electrophoresis. J. Dairy Sci. 77:2177-2190.

Lara-Villoslada, F., M. Olivares, J. Jiménez, J. Boza, and J. Xaus. 2004. Goat milk is less immunogenic than cow milk in a murine model assay of atopy. J. Pediatr. Gastroenterol. Nutr. 39:354360.

Lara-Villoslada, F., M. Olivares, and J. Xaus. 2005. The balance between caseins and whey proteins in cow's milk determines its allergenicity. J. Dairy Sci. 88:1654-1660.

Martín Esteban, M., M. C. García Ara, and C. Pascual Marcos. 1999. Alergia inmediata a alimentos en el niño: Aspectos etiológicos, patogénicos y diagnósticos. Bol. Pediatr. 39:140-147.

McLaughlan, P., K. J. Anderson, and R. R. A. Coombs. 1981. An oral screening procedure to determine the sensitizing capacity of infant feeding formulae. Clin. Allergy 11:311-318.

Muñoz Martín, T., B. de la Hoz Caballer, F. Marañón Lizana, R. González Mendiola, P. Prieto Montaño, and M. Sánchez Cano.
2004. Selective allergy to sheep's and goat's milk protein. Allergol. Immunopathol. (Madr.) 32:39-42.

Ovary, Z., and N. L. Warner. 1972. Electrophoretic and antigenic analysis of mouse and guinea pig anaphylactic antibodies. J. Immunol. 108:1055-1062.

Pahud, J. J., J. C. Monti, and R. Jost. 1985. Allergenicity of wey protein: Its modification by tryptic in vitro hydrolysis of the protein. J. Pediatr. Gastroenterol. Nutr. 4:408-413.

Parish, W. E., C. B. Richards, N. E. France, and R. R. A. Coombs, 1964. Further investigations on the hypothesis that some cases of cot-death are due to a modified anaphylactic reaction to cows' milk. Int. Arch. Allergy 24:215-221.

Park, Y. W. 1994. Hypo-allergenic and therapeutic significance of goat milk. Small Rumin. Res. 14:151-159.

Perlman, F. 1977. Food allergens. Pages 279-316 in Immunological Aspects of Foods. N. Catsimpoolas, ed. AVI Publ. Co. Inc. Westport, CT.

Recio, I., M. L. Pérez-Rodríguez, L. Amigo, and M. Ramos. 1997. Study of the polymorphism of caprine milk caseins by capillary electrophoresis. J. Dairy Res. 64:515-523.

Restani, P. 2004. Goat milk allergenicity. J. Pediatr. Gastroenterol. Nutr. 39:323-324

Restani, P., B. Beretta, A. Fiocchi, C. Ballabio, and C. L. Galli. 2002. Cross-reactivity between mammalian proteins. Ann. Allergy Asthma Immunol. 89:11-15.

Sampson, H. A., and D. G. Ho. 1997. Relationship between foodspecific $\operatorname{IgE}$ concentrations and the risk of positive food challenges in children and adolescents. J. Allergy Clin. Immunol. 100:444451.

Saperstein, S. 1974. From Pages 257-280 in Lactation: A comprehensive treatise. Vol. III. B. L. Larson, and V. R. Smith, ed. Academic Press, New York, NY.

Sokal, R. R., and F. J. Rohlf. 1979. Análisis de frecuencias. pp. 601-702 in Biometría. Principios y métodos estadísticos en la investigación biológica. H. Blume ed. Madrid, Spain.

Stanley, J. D., and G. A. Bannon. 2003. Molecular mechanisms of food allergy. pp. 369-379 in Molecular Nutrition. J. Zempleni and H. Daniel, ed. CABI Publishing, Cambridge, MA. USA.

Statgraphics. 2001. User manual: Statistical Graphics System by Statistical Graphics Corporation. Statgraphics, Herndon, VA.

Van Hekken, D. L., and M. P. Thompson. 1992. Application of FhastSystem $^{\mathrm{r}}$ to the resolution of bovine milk proteins on ureapolyacrylamide gel electrophoresis. J. Dairy Sci. 75:1204-1210.

Wal, J. M. 2001. Structure and function of milk allergens. Allergy $56(\mathrm{~S} 67): 35-38$. 